\title{
ViRgin MALE MATING ADVANTAGE IN SAGEBRUSH CRICKETS: NO ROLE FOR AN ACOUSTICALLY- Mediated Female Preference
}

\author{
SCOTT K. SAKALUK $\downarrow$ PAMELA L. BRADY $\downarrow$ TRACIE M. IVY $\downarrow$ MARION C. SAKALUK \\ JENNIFER M. SCHAUS $\downarrow$ BEHAVIOR, ECOLOGY, EVOLUTION AND SYSTEMATICS SECTION \\ DEPARTMENT OF BIOLOGICAL SCIENCES \\ ILLINOIS STATE UNIVERSITY $\downarrow$ NORMAL
}

\section{$\downarrow \quad$ INTRODUCTION}

The sagebrush cricket, Cyphoderris strepitans, is one of only five extant species belonging to an obscure orthopteran lineage, the Haglidae, closely related to the true crickets (Gryllidae) and katydids (Tettigoniidae) (Morris \& Gwynne 1978). C. strepitans occurs exclusively in mountainous areas of the western United States, where it is found primarily in high-altitude sagebrush meadow habitat. Adults become sexually active in late spring, shortly after snow melt, and remain active for the following 4-6 weeks. The acoustic signals produced by males function to attract females (Snedden \& Irazuzta 1994), thereby enhancing male mating opportunities (Snedden \& Sakaluk 1992). Copulation is initiated when a receptive female climbs onto the dorsum of a male, at which time he attempts to transfer a spermatophore. During copulation, the female feeds on the male's fleshy hind wings and bodily fluids leaking from the wounds she inflicts.

Previous field studies involving the markrecapture of a large number of males have shown that once a male has mated, his probability of obtaining an additional copulation is reduced relative to that of a virgin male securing his first mating (Morris et al. 1989). One explanation for the virgin-male mating advantage is that non-virgin males, having lost a substantial portion of their energy reserves through sexual cannibalism by females and the transfer of a large spermatophore, may be unable to sustain the costly acoustical signaling activity required to attract additional females. In support of the "male fatigue" hypothesis, electronic assays of male signaling behavior have shown that virgin male $C$. strepitans call for significantly longer durations than recently mated males (Sakaluk et al. 1987; Sakaluk \& Snedden 1990).

An alternative hypothesis to account for the virgin-male mating advantage is that females preferentially mate with virgin males, because these males have greater material resources to offer females than do non-virgin males. If the acoustic structure of males' signals are systematically altered by the loss of hind-wing material underlying the sound-producing tegmina, then females could potentially discriminate against mated males through reduced phonotaxis to their calls. Indeed, acoustic analyses of digitized calls of virgin and non-virgin males indicate possible differences in the amplitude, and perhaps, spectral components of the signals (Snedden \& Greenfield 1995). Hence, acoustically mediated female mate choice could contribute to the differential mating success of virgin and non-virgin males as much or more than any difference in 
signaling duration, but this possibility has not previously been tested.

One difficulty in distinguishing between the male-fatigue and mate-choice hypotheses as they apply to the virgin male mating advantage, is that non-virgin males may be disadvantaged in both contexts. In the present study, we circumvented this problem by altering the hind wings of virgin males in a way that mimicked the wing loss of non-virgin males, without the attendant costs of copulation. If loss of hind wing material systematically alters the structure of males' signals, and females rely on these differences to preferentially orient to virgin males, then the mate-choice hypothesis predicts that experimental removal of hind wing material from virgin males should lead to a reduction in their mating success relative to unmanipulated virgin males.

\section{METHODS}

\section{FIELD STUDY}

A mark-recapture study was conducted from May 23 to June 18, 1997 in Grand Teton National Park, Wyoming. A rectangular study plot approximately $120 \mathrm{~m} \mathrm{X} 180 \mathrm{~m}$ was established in sagebrush meadow habitat adjacent to the Snake River at Deadman's Bar. During the early portion of the breeding season, we attempted to capture and mark all of the virgin males present in the study plot. Males were found at night by orienting to their calls and using head lamps to determine their exact location within a sagebrush bush. The mating status of males was determined by examining their hind wings for the wounds inflicted by females; only virgin males, as evidenced by intact wings, were used in experimental treatments. Each virgin male was placed in a collecting vial, numbered to correspond with a surveyor's flag placed at the capture location, and transported to University of Wyoming-National Park Service Research Station, approximately $30 \mathrm{~km}$ away, for processing.

Captured males were randomly assigned to either of two treatments in which the amount of hind-wing material retained by males was experimentally manipulated. In one treatment, we surgically removed one hind wing from the male by severing it at its point of insertion using fine dissecting scissors (non-virgin mimics). This treatment was designed to mimic the loss of wing material that occurs at mating. Hind wing removal resulted in little bleeding owing to the rapid coagulation of haemolymph, in contrast to normal matings during which continued feeding by females promotes a steady flow of haemolymph. In a second treatment, small lesions were made in both hind wings of the male, but the hind wings were otherwise left intact (sham-control males). This operation controls for any detrimental effects of haemolymph loss in males of the first treatment. Each male was marked individually with a numbered plastic tag secured to the pronotum with cyanoacrylic glue. Fluorescent paint was applied to the pronotum around the numbered tag, and to the femora of each individual. Portable ultraviolet lanterns, the illumination of which causes the paint to fluoresce, subsequently were used to facilitate cricket recapture. The following evening at sunset, marked males were returned to their respective points of capture. We marked and released a total of 106 males (53 non-virgin mimics, 53 sham-control).

After experimental males were released, males were recaptured and examined for evidence of mating activity regularly over the course of the breeding season, usually every second night, weather permitting. The number of males recaptured on any given night varied from $1-44(\mathrm{~N}$ $=18$ nights). Mating was inferred by loss of hind wing material in both treatments. If females rely on differences in males' acoustic signals to preferentially mate with virgin males, we predicted that the mating success of sham-control males (those with intact hind wings) would be significantly higher than non-virgin mimics (virgin males lacking one hind wing).

\section{LABORATORY STUDY - UNIVERSITY OF WYOMING-NATIONAL PARK SERVICE RESEARCH CENTER}

If females' mating preferences were predicated on the amount of wing material males had to offer, such preferences could be exercised either in the context of long-distance mate attraction or through discrimination that takes place following pair formation. While the field study adequately addresses the former possibility, the rarity with which naturally occurring copulations are detected in the field precludes any assessment of female choice at mating as it occurs in the natural situation. Accordingly, we conducted a laboratory study in which we employed time-lapse video photography to record the mating behavior of males whose hind 
wings were experimentally altered as in the field study. Virgin males and females of unknown mating status were collected at two sites within the park (Deadman's Bar and Pacific Creek) and at an additional site in Bridger-Teton National Forest. Captured crickets were transported back to the research center and maintained according to standard procedures (Snedden \& Sakaluk 1992; Eggert \& Sakaluk 1994). Males were assigned to either of the two experimental treatments, 1) nonvirgin mimics or 2) sham-control males. Males were treated the morning after their capture and used in mating trials the second evening following their capture, thereby allowing them sufficient time to recover from their operations.

Each night of the study, one or two males from each of the two treatments were paired with females at about $1900 \mathrm{~h}$, and their mating activity monitored over a 12-hour period using time-lapse video photography. Nighttime recording was facilitated by the illumination provided by a $25-\mathrm{W}$ red light bulb. Experimental pairs were confined in a Plexiglas viewing chamber $(17 \times 12 \times 3.5 \mathrm{~cm})$, divided into four equal compartments to prevent contact between crickets of different pairs, each of which contained a short stick to serve as a calling perch. Upon review of video recordings, we determined: 1) the time spent calling by each male during the trial, measured as the number of 5-min intervals within which stridulation occurred, 2) the number of times each male was mounted by the female, and 3) the number of matings (mounts resulting in successful transfer of the spermatophore). Matings were easily scored, as the spermatophore remains attached outside the female's body after copulation and is readily visible in video recordings. A total of 22 pairs, 11 in each treatment, were recorded. Experimental individuals were used in one trial only and returned to the field the subsequent night.

\section{$\downarrow \quad$ RESUlts AND CONCLUSIONS}

\section{FIELD STUDY}

Ninety marked males ( $85 \%$ of total) were recaptured at least once, and recapture frequencies were homogeneous across treatments (likelihood ratio chi-square, $\mathrm{L}=1.80, \mathrm{p}=0.18$ ). The proportions of males that mated across experimental treatments were not significantly different (Figure 1; likelihood ratio chi-square, $\mathrm{L}=0.10, \mathrm{p}=$
0.75). These results suggest that males lacking hind wing material are not compromised in their ability to attract females. We conclude, therefore, that the virgin-male mating advantage is not mediated by acoustically based, female mating preferences.

Figure 1. Mating success of males lacking one hind wing and shamoperated males. There was no significant difference in mating success across treatments.
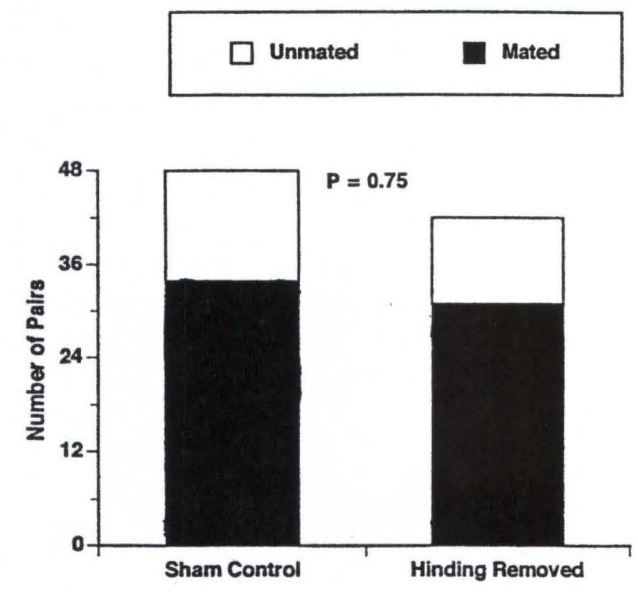

\section{LABORATORY STUDY}

The percentage of males that mated was exactly the same in both treatments $(73 \%)$. These results corroborate the results of the field study, and suggest that even after pair formation, any alteration in males' acoustic signals stemming from the loss of hind wing material does not diminish male attractiveness.

\section{$\downarrow \quad$ ACKNOWLEDGMENTS}

We thank Chad Johnson and Madeline Ostrander for field and laboratory assistance. The study was supported by grants from the National Science Foundation (IBN-9601042 and REU Supplement) and Illinois State University to S.K.S.

\section{LITERATURE Cited}

Eggert A-K, Sakaluk SK (1994). Sexual cannibalism and its relation to male mating success in sagebrush crickets, Cyphoderris strepitans (Haglidae: Orthoptera). Anim Behav 47: 1171-1177. 
Morris, G.K. \& Gwynne, D.T. 1978 Geographical distribution and biological observations of Cyphoderris (Orthoptera: Haglidae) with a description of a new species. Psyche 85, 147-167.

Morris, G.K., Gwynne, D.T., Klimas, D.E. \& Sakaluk, S.K. 1989 Virgin male mating advantage in a primitive acoustic insect (Orthoptera: Haglidae). J. Insect Behav. 2, 173-185.

Sakaluk SK, Morris GK, Snedden WA (1987) Mating and its effect on acoustic signaling behavior in a primitive orthopteran, Cyphoderris strepitans (Haglidae): the cost of feeding females. Behav. Ecol. Sociobiol. 21:173-178.

Sakaluk SK, Snedden WA (1990) Nightly calling durations of male sagebrush crickets, Cyphoderris strepitans: size, mating, and seasonal effects. Oikos 57:153-160.
Snedden, W.A. \& Irazuzta, S. 1994 Attraction of female sagebrush crickets to male song: the importance of field bioassays. J. Insect Behav. 7, 233-236.

Snedden, W.A. \& Greenfield, M.D. 1995. Virgins are louder: the effect of mating on acoustic signaling in sagebrush crickets. In: University of Wyoming - National Park Service Research Center, 19th Annual Report (H.J. Harlow \& M. Harlow, eds.), pp. 78-83.

Snedden, W.A. \& Sakaluk, S.K. 1992 Acoustical signalling and its relation to male mating success in sagebrush crickets. Anim. Behav. 44, 633-639. 